\title{
Aortic valve replacement in elderly patients with aortic stenosis
}

E Straumann, W Kiowski, I Langer, E Grädel, P Stulz, D Burckhardt, M Pfisterer, F Burkart

Division of Cardiology E Straumann W Kiowski I Langer D Burckhard M Pfisterer F Burkart

Department of Cardiothoracic Surgery, University Hospital of Basle, Basle, Switzerland E Grädel P Stulz

Correspondence to: DrWolfang Kiowst Dr Wolfgang Kiowski Division of Cardiology, Department of Internal Medicine, University 100 , Hospital, Rämistrasse CH-8091, Zurich, Switzerland.

Accepted for publication 13 October 1993

\begin{abstract}
Objective-To assess the risk of aortic valve replacement and long-term followup in elderly patients with dominant aortic stenosis.

Design-Retrospective analysis of patients who had aortic valve replacement over a 10 year period and were routinely seen in an outpatient clinic.
\end{abstract}

Setting-University hospital.

Patients-93 patients aged $\geqslant 60$ and 47 patients $\geqslant 70$ years with symptomatic aortic stenosis undergoing aortic valve replacement.

Main outcome measures-Early and late mortality in different age groups. Influence of preoperative signs and symptoms on overall outcome.

Results-The proportion of patients older than 70 years increased from $11 \%$ in 1978 to $54 \%$ in 1986 . Perioperative mortality was $3 \cdot 6 \%$ and mortality after 2 and 5 years was $9 \%$ and $13 \%$ respectively. Survival was similar $(85 \%$ and $83 \%$, respectively) in patients aged 60-69 years (group 1, $n=93$, mean age $64.5(2 \cdot 7)$ and patients aged $\geqslant 70$ years (group $2, n=$ 47, mean age $72 \cdot 6(2 \cdot 5)$ ). Additional coronary artery disease and coronary bypass grafting did not significantly affect survival. The cardiothoracic ratio was inversely related to survival (Cox regression, $p<0.05)$. Preoperative symptoms (syncope, angina pectoris, and dyspnoea) were similar in both patient groups. After a mean (SD) follow up of 51 (33) months $96 \%$ of surviving patients were in NYHA functional class I or II with no difference between the two age groups. Similarly, the cardiothoracic ratio and Sokolow index decreased to near normal values in both age groups.

Conclusion-The risk of aortic valve replacement in patients with dominant aortic stenosis is low and not significantly influenced by age. Therefore replacement may be performed without increased risk in elderly patients and with a good longterm outcome.

(Br Heart f 1994;71:449-453)

In Europe and the United States aortic stenosis has become the most common valve disease in adults. ${ }^{1}$ The clinical spectrum of aortic stenosis has shifted from post-inflammatory to degenerative lesions and aortic stenosis is most prevalent in older patients. ${ }^{12}$ Aortic stenosis is a progressive disease ${ }^{34}$ that progresses more rapidly in patients with degenerative calcifying aortic stenosis and in older patients. ${ }^{25}$ Because valve replacement is the only effective treatment and because older patients are increasingly presenting with symptomatic aortic stenosis we assessed early and late mortality and improvement of symptoms in elderly patients with dominant aortic stenosis undergoing aortic valve replacement. We also evaluated the influence of preoperative signs and symptoms on overall outcome.

\section{Patients and methods}

PATIENTS

A total of 140 patients aged $\geqslant 60$ years (range 60-81 years, 96 men and 44 women) with dominant, symptomatic aortic stenosis underwent aortic valve replacement in our hospital between 1977 and 1986. All had angina pectoris or dyspnoea or both and $73 \%$ were in NYHA functional class III or IV. There was a history of syncope in $42 \%$ and concomitant aortic regurgitation in $87 \%$. Operation was elective in 134 and urgent in six patients. All patients were operated on by the same surgical team using standard cardiopulmonary bypass and cold blood potassium cardioplegia in 108 patients for myocardial protection or coronary perfusion at the beginning of the study period in 32 patients. We used an interrupted suture technique. Mechanical prostheses were implanted in 119 (St JudeMedical in 59, Björk-Shiley in 40, Omnicarbon in 13, Duromedics in six, and Starr-Edwards in one) and bioprostheses were used in 21 patients (Ionescu-Shiley in 17, and Carpentier-Edwards in four).

Bioprostheses were used only when longterm anticoagulation with warfarin was contraindicated or patients were not expected to outlive the tissue prostheses.

PREOPERATIVE INVESTIGATIONS

Left heart catheterisation was performed preoperatively in all patients for direct measurement of aortic pressure gradient (pull-back method) and assessment of concomitant coronary artery disease, aortic regurgitation, and left ventricular ejection fraction.

Coronary artery disease was defined as narrowing by $75 \%$ or more of the lumen of at least one vessel. Aortic regurgitation was graded angiographically: as grade I (just visible contrast regurgitation), grade II (contrast regurgitation to the apex, but fully washed out 
after each ejection), grade III (contrast accumulation), and grade IV (free aortic regurgitation).

\section{FOLLOW UP}

After discharge patients were routinely seen in our outpatient clinic 3 and 12 months after operation and usually every year thereafter. We reviewed their records for symptoms (syncope, angina pectoris, dyspnoea), clinical findings, cardiothoracic ratio on chest $x$ rays and 12 lead surface ECG preoperatively, at discharge, 3 months postoperatively, and at the last available follow up (at a mean of 51 (33) months after operation).

The following perioperative complications were assessed: newly developed atrial fibrillation present at discharge, bradycardia requiring pacemaker implantation, ventricular arrhythmias (ventricular tachycardia and ventricular fibrillation), bleeding requiring reoperation, myocardial infarction, stroke, haemodynamically significant pericardial effusion, pneumonia, wound infections, and sternal wound revision.

Survival was assessed as time from operation to last follow up examination. For patients not reporting for the last, scheduled visit, the time of death was ascertained by asking the patient's private physician or relatives.

At the last follow up examination patients were also asked to judge their improvement in physical limitation after operation as excellent/good, satisfactory, or unsatisfactory.

\section{STATISTICAL ANALYSIS}

Values are given as mean (SD). Student's $t$ test, Chi square test, and repeated measures

Table 1 Preoperative signs and symptoms in 140 patients with dominant aortic stenosis

\begin{tabular}{|c|c|c|c|c|c|}
\hline \multirow[b]{2}{*}{ Variable } & \multicolumn{2}{|c|}{ Group 1 (60-69 yr) } & \multicolumn{2}{|c|}{ Group $2(\geqslant 70 y r)$} & \multirow[b]{2}{*}{ p Value } \\
\hline & $n$ & Result & $n$ & Result & \\
\hline Age (years) (mean (SD)) & 93 & $64 \cdot 5 \pm 2 \cdot 6$ & 47 & $72 \cdot 6(2 \cdot 5)$ & 0.0001 \\
\hline $\operatorname{Sex}(M / F)$ & 93 & $68 / 25$ & 47 & $29 / 18$ & $0 \cdot 17$ \\
\hline Syncope & 93 & $37(40 \%)$ & 47 & $22(47 \%)$ & 0.62 \\
\hline $\begin{array}{l}\text { Angina pectoris } \\
\text { (NYHA III/IV) }\end{array}$ & 93 & $38(41 \%)$ & 47 & $21(45 \%)$ & $0 \cdot 83$ \\
\hline Dyspnoea (NYHA III/IV) & 93 & $60(65 \%)$ & 47 & $29(62 \%)$ & $0 \cdot 85$ \\
\hline Heart rate (bpm) (mean (SD)) & 93 & $76(14)$ & 47 & $75(12)$ & $0 \cdot 76$ \\
\hline Cardiothoracic ratio (mean (SD)) & 90 & $0.53(0.06)$ & 45 & $0.53(0.06)$ & 0.75 \\
\hline Sokolow index (mV) (mean (SD) & 84 & $3 \cdot 9(1 \cdot 2)$ & 39 & $4 \cdot 3(1 \cdot 8)$ & $0 \cdot 15$ \\
\hline
\end{tabular}

Numbers of patients available for evaluation are indicated.

Table 2 Preoperative haemodynamic findings in 140 patients with dominant aortic stenosis

\begin{tabular}{|c|c|c|c|c|c|}
\hline \multirow[b]{2}{*}{ Variable } & \multicolumn{2}{|c|}{ Group $1(60-69 y r)$} & \multicolumn{2}{|c|}{ Group $2(\geqslant 70 y r)$} & \multirow[b]{2}{*}{$p$ Value } \\
\hline & $n$ & Result & $n$ & Result & \\
\hline PCWP (mm Hg) & 65 & $17(10)$ & 33 & $18(8)$ & 0.62 \\
\hline $\mathrm{EF}((\%) \mathrm{RNA})$ & 12 & $56(19)$ & 13 & $50(15)$ & 0.40 \\
\hline EF ((\%) Cath) & 34 & $53(18)$ & 16 & $55(19)$ & $0 \cdot 80$ \\
\hline Systolic BP (mm Hg) & 83 & $138(24)$ & 44 & $142(34)$ & 0.41 \\
\hline Diastolic BP (mm Hg) & 83 & $73(12)$ & 44 & $69(14)$ & $0 \cdot 10$ \\
\hline LVSP (mm Hg) & 59 & $212(32)$ & 33 & $214(42)$ & $0 \cdot 80$ \\
\hline LVEDP (mm Hg) & 55 & $31(10)$ & 30 & $26(10)$ & 0.04 \\
\hline$\Delta \mathrm{P}$ syst $(\mathrm{mm} \mathrm{Hg})$ & 58 & $74(26)$ & 31 & $72(26)$ & 0.95 \\
\hline AVA $\left(\mathrm{cm}^{2}\right)$ & 41 & $0.48(0.16)$ & 25 & $0.45(0.18)$ & 0.54 \\
\hline $\mathrm{CI}\left(1 / \mathrm{min} / \mathrm{m}^{2}\right)$ & 79 & $2.90(0.70)$ & 35 & $2 \cdot 80(0 \cdot 80)$ & $0 \cdot 48$ \\
\hline Aortic regurgitation & 92 & $83(90 \%)$ & 47 & $40(85 \%)$ & 0.62 \\
\hline CAD & 93 & $31(33 \%)$ & 47 & $19(40 \%)$ & 0.74 \\
\hline
\end{tabular}

Numbers of patients available for evaluation are indicated, PCWP, pulmonary capillary wedge pressure; EF, ejection fraction; RNA, radionuclide angiography; Cath, left heart catheterisation $\mathrm{BP}$, aortic blood pressure; LVSP, left ventricular peak systolic pressure; LVEDP, left ventricula end diastolic pressure; $\Delta \mathrm{P}$ syst, systolic pressure gradient; AVA, aortic valve area; CI, cardiac index; $\mathrm{CAD}$, coronary artery disease. analysis of variance (ANOVA) were used as appropriate. Survival rates were calculated according to the method of Kaplan-Meier. The influence of age, preoperative NYHA functional class, ejection fraction, calculated aortic valve area, left ventricular pressures, presence of coronary artery disease and concomitant bypass grafting on survival was estimated using the Cox proportional hazard model. All calculations were performed using the Systat statistical package. p Values of $<0.05$ were regarded as statistically significant.

\section{Results}

The mean age of the study population was $67 \cdot 2(4 \cdot 6)$ years. Ninety three patients were aged 60-69 (mean 64.5 (2.6)) years (group 1) and 47 patients were $70-81$ (mean $72 \cdot 6(2 \cdot 5)$ ) years (group 2). The proportion of patients $\geqslant 70$ years increased from $11 \%$ in 1978 to $54 \%$ in 1986 .

\section{PREOPERATIVE FINDINGS AND SYMPTOMS}

Table 1 summarises the preoperative characteristics of the patients. There were no significant differences in sex distribution; incidence of syncope, severe angina pectoris, and dyspnoea; and heart rate between the age groups. The cardiothoracic ratio and Sokolow-index were increased in both groups, indicating similar degrees of left ventricular hypertrophy.

Preoperative haemodynamic findings (table 2) were also similar in both groups except for left ventricular end diastolic pressure which was slightly but significantly higher in group 1 patients $(\mathrm{p}<0.05)$. The peak-to peak pressure gradient over the aortic valve was similar in both age groups (table 2).

The ejection fraction measured by left ventriculography during left heart catheterisation (mean $54 \%$, range $18-82 \%$ ) and by radionuclide angiography (mean $52 \%$, range $15-82 \%$ ) was similar in both age groups and was $<40 \%$ in $28 \%$ of group 1 and $24 \%$ of group 2 .

Concomitant aortic regurgitation was present in $87 \%$. The frequency and severity of concomitant aortic regurgitation were similar in both groups: grade I, II, and III regurgitation was seen in $22 \%, 25 \%$, and $40 \%$ of group 1 patients and in $21 \%, 32 \%$, and $32 \%$ of group 2 patients respectively. Grade IV regurgitation was not seen. The cardiothoracic ratio was similar in patients with grade III $(0.53(0.67))$ or lesser degrees of aortic regurgitation $(0.52(0.51) \mathrm{NS})$.

Coronary artery disease was present in $33 \%$ of group 1 patients ( $8 \%$ had three vessel disease), and in $40 \%$ of group 2 patients $(13 \%$ had three vessel disease, NS). Revascularisation procedures were performed in 25 of 30 group 1 and in 12 of 19 group 2 patients $\left(\mathrm{p}=0 \cdot 11, \chi^{2}\right)$.

IN-HOSPITAL PERIOPERATIVE COMPLICATIONS The length of hospital stay was similar in both groups $(20.6(5.8)$ days in group 1 and 22.5 $(16.4)$ days in group 2). In total, there were 

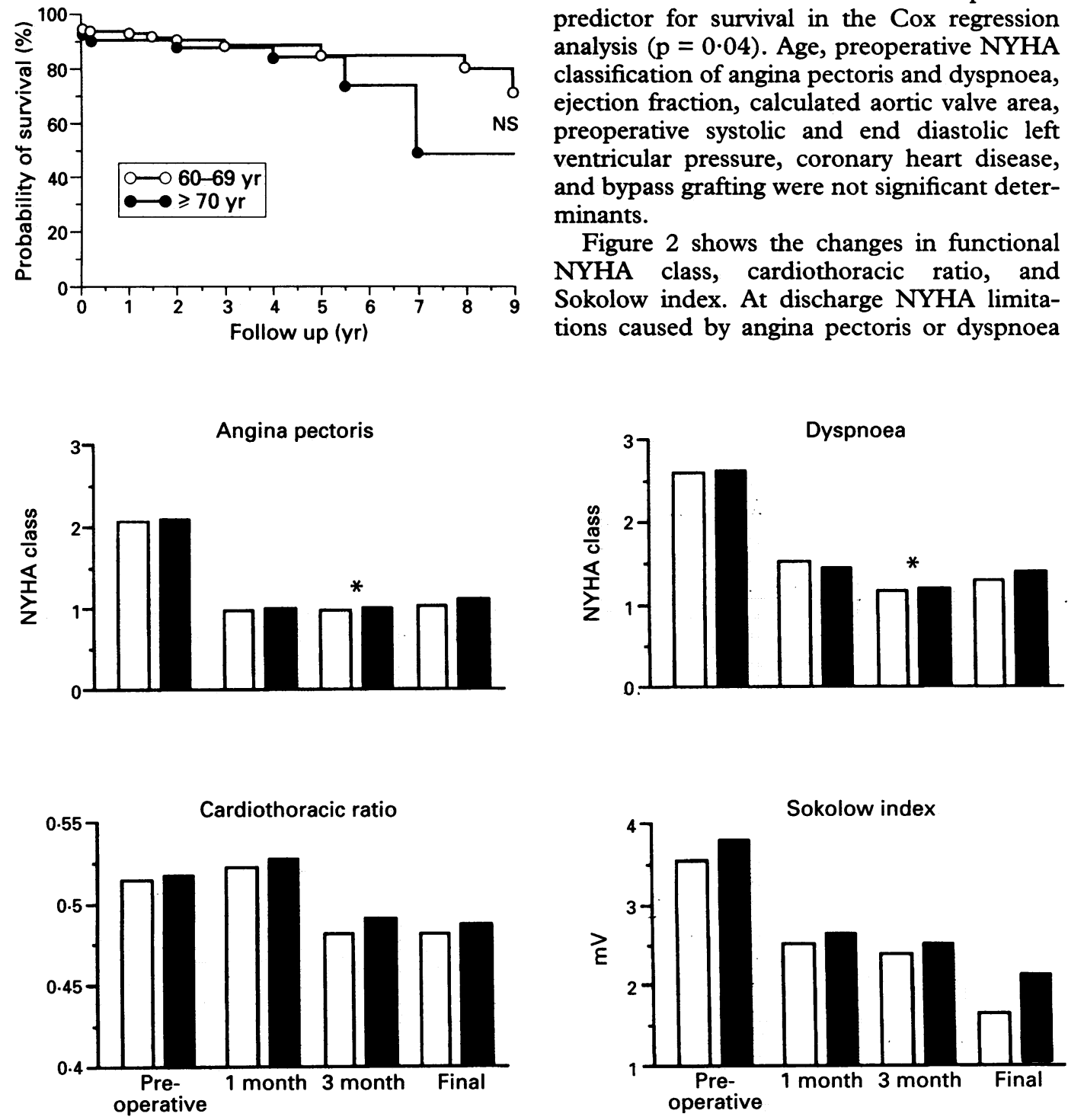
predictor for survival in the Cox regression analysis $(p=0.04)$. Age, preoperative NYHA classification of angina pectoris and dyspnoea, ejection fraction, calculated aortic valve area, preoperative systolic and end diastolic left ventricular pressure, coronary heart disease, and bypass grafting were not significant determinants.

Figure 2 shows the changes in functional NYHA class, cardiothoracic ratio, and Sokolow index. At discharge NYHA limitations caused by angina pectoris or dyspnoea

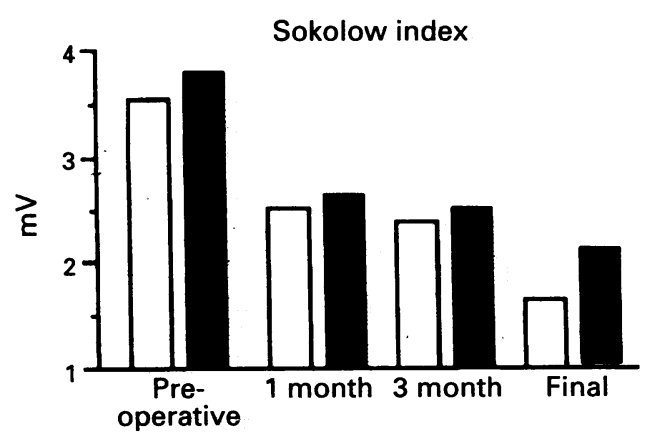

Table 3 In-hospital complications in 140 patients undergoing aortic valve replacement

\begin{tabular}{ll}
\hline Complications & Events $(n)$ \\
\hline New atrial fibrillation & 12 \\
Ventricular arrhythmias (VT/VF) & $6(1)$ \\
Bleeding requiring reoperation & 5 \\
Stroke & $3(1)$ \\
Reoperation because of & 2 \\
subvalvar obstruction & $2(1)$ \\
Perioperative infarction & $2(1)$ \\
Pneumonia & 3 \\
Sternal wound revision/ & $1(1)$ \\
wound infection & 1 \\
Pertic rupture & 1 \\
Severe right heart failure & 1 \\
Pericardial effusion & \\
requiring pericardiocenteses & $39(5)$ \\
Total &
\end{tabular}

Numbers in parentheses and deaths attributable to the respective complication. AV, atrioventricular; VF, ventricular fibrilation; VT, ventricular tachycardia.

39 perioperative complications (table 3 ). Complications were as common in the younger patients $(n=26,28 \%)$ as in the older patients $(n=13,28 \%)$.

\section{FOLLOW UP}

Six patients were lost to follow up. Follow up was somewhat shorter in group 2 patients

Figure 1 Probability of survival after aortic valve replacement was similar in patients aged 60-69 years or $\geqslant 70$ years. because in recent years more elderly patients had operations $(4.6(2 \cdot 9)$ years in group 1 and $3.5(2.3)$ years in group $2(p=0.03))$.

There were two $(1 \cdot 4 \%)$ operative deaths, both in group 1, and hospital mortality (all deaths within 30 days including operative deaths) was $3.6 \%(n=5)$, with no significant difference between group $1(n=4,4.3 \%)$ and group $2(\mathrm{n}=1,1.9 \%)$.

During long-term follow up 16 patients died. There was a total of 21 deaths, with cardiac deaths in seven patients (33\%). Four patients $(19 \%)$ died of major bleeding (two intracerebral haemorrhages (one early, one late), one trauma, and one from aortic rupture); three patients (14)\% died of cancer; two $(10 \%)$ died from pneumonia (one early, one late) and in five patients $(24 \%)$ the mode of death was not known.

Thus the probability of survival 1,5 , and 8 years after operation was $92.6 \%$ (125 patients at risk), $84 \cdot 1 \%(n=55)$, and $75 \cdot 5 \%(n=20)$ respectively for all patients. Figure 1 shows that the probability of survival was not significantly different in the older and the younger patient groups.

Of all factors evaluated only the preoperative cardiothoracic ratio was an independent

Figure 2 Preoperative and postoperative NYHA classification of angina pectoris, dyspnoea, cardiothoracic ratio, and Sokolow index in patients aged 60-69 years or $\geqslant 70$ years. Assessment was performed before operation, 1 and 3 months after surgery, and at final follow up examination. Both age groups showed persistent and similar decreases in signs and symptoms over time $(p<0.01$ *, ANOVA). 
had already decreased similarly in both age groups and there were no significant differences after 3 months and at the last follow up examination (repeated measures ANOVA). Similarly the cardiothoracic ratio decreased in both age groups after discharge to normal or near normal values and then remained unchanged until the last examination. The Sokolow index decreased progressively up to the last examination in both groups, but remained slightly higher in the older patient group at the last examination (fig 2).

At last follow up examination $91 \%$ of surviving patients reported an excellent or good improvement in physical capacity, $8 \%$ judged it as satisfactory, and only one patient (group 2) judged it to be unsatisfactory (corresponding values for groups 1 and 2: $90.6 \%, 9 \cdot 4 \%$, $0 \%$ v $93 \%, 5 \cdot 7 \%, 2 \cdot 3 \%$, NS).

\section{Discussion}

In the early days of aortic valve replacement, overall in-hospital mortality was $7-12 \%,{ }^{6-8}$ and in patients over 60 years of age it was as high as $20 \% .^{69-15}$ Depending on age at operation, preoperative condition, and time of follow-up long-term mortality ranged from $4.6 \%$ to $10 \cdot 4 \%$ per year. ${ }^{13} 16-23$ Since then surgical outcome has improved substantially as the result of advances in anaesthesia, myocardial protection, and postoperative care..$^{24-27}$

Our data in an elderly population with dominant aortic stenosis accord with these trends towards improved survival and show a low perioperative $(3.6 \%)$ and long-term mortality $(13 \%$ at 5 years, hospital deaths included) after aortic valve replacement, irrespective of age. The low perioperative mortality may be due in part to the low incidence of urgent operations, because the risk is higher with urgent surgery. ${ }^{28-30}$ In terms of the severity of preoperative symptoms (NYHA class III and IV impairment in $73 \%$ ) the overall outcome in our patients was particularly good, and compares well with recent reports in which patients were clearly younger. ${ }^{24} 25$

Aortic valve replacement has also been reported in patients considerably older than ours. $^{30-32}$ The early mortality $\left(5 \cdot 7 \%^{32}\right.$ and $30 \%{ }^{30}$ ) suggested, not unexpectedly, that the risk in octogenarians was substantially higher than in our study group of patients aged between 70 and 80 years. However, late survival has also been reported to be excellent in such patients ${ }^{3132}$ and in one instance was found to be even better than that of an age and sex matched control group. ${ }^{31}$

Our data show also that quality of life and functional capacity improved substantially in all patients. Thus at the last follow up examination $91 \%$ of surviving patients reported good or excellent improvement in their physical capacity and $96 \%$ were in NYHA functional class I or II compared with NYHA III or IV in $73 \%$ before operation. The cardiothoracic ratio decreased to normal or near normal values within 3 months in both groups, whereas left ventricular hypertrophy seemed to regress progressively up to the last examination. This continuing reduction of left ventricular hypertrophy accords with a study in which angiographically assessed left ventricular muscle mass fell continuously during a follow up of up to 70 months after aortic valve replacement. ${ }^{33} 34$

Because there are no alternatives to valve replacement our results and those of others are particularly encouraging. The benefits of balloon dilatation of the aortic valve were short-lived: in a recent report restenosis occurred in over $50 \%$ of patients within one to two years. Furthermore, the best long-term results were obtained in patients who would have been expected to have excellent longterm results after aortic valve replacement. ${ }^{35}$

PREDICTORS OF MORTALITY AND LONG-TERM SURVIVAL

We found that the cardiothoracic ratio was the only independent predictor of survival in a Cox regression model that evaluated nine clinical and haemodynamic variables. Similar observations have been reported before, ${ }^{162425}$ but unlike others 2124303637 we did not identify additional predictors such as preoperative ejection fraction, coronary artery disease, NYHA classification, or presence of atrial fibrillation. ${ }^{38}$ On theoretical grounds significant concomitant aortic regurgitation might lead to a greater increase in cardiothoracic ratio that might explain the impact of cardiothoracic ratio in our study. However, the cardiothoracic ratio in our patients with grade III regurgitation was no different from that in patients with lesser degrees of regurgitation. The discrepancies between our findings and those of others may also be explained in part by the fact that many of the variables shown to be significant by univariate analysis may not be by the multivariate analysis that we used. Moreover, patients with either dominant aortic stenosis or dominant aortic regurgitation were sometimes assessed jointly ${ }^{24}$ despite the fact, that the two lesions differ in many aspects. Furthermore, we measured preoperative ejection fraction only in 75 of our 140 patients. However, in a report on open chest cardiac surgery in octogenarians the ejection fraction was predictive of early mortality but not of late mortality. ${ }^{31} \mathrm{We}$, like others, ${ }^{39-41}$ found that concomitant coronary artery disease or coronary artery bypass grafting did not significantly affect survival. In contrast, others found that late mortality was higher in patients with aortic stenosis who had concomitant coronary artery disease than in those who had stenosis alone ${ }^{4243}$ and the Veterans Administration valve study identified the presence of three vessel disease as the most powerful independent predictor of hospital mortality after aortic valve replacement. ${ }^{36}$ Similarly, operative risk was higher in combined aortic and coronary artery disease ${ }^{44}$ and in patients undergoing additional coronary artery bypass grafting. 27313245 This discrepancy cannot readily be explained but it may arise because only $9 \%$ of our patients had three vessel disease. Furthermore, coronary artery bypass grafting was less likely to be 
performed in those of our patients who were older than 70 . This approach is supported by a recent review that questioned the evidence that coronary artery bypass grafting at the time of aortic valve replacement does indeed improve survival. ${ }^{46}$

Aortic stenosis is increasingly a disease of the elderly. Aortic valve replacement is the only successful treatment and it has become a safe procedure even in elderly patients with advanced functional impairment. Long-term survival and quality of life after aortic valve replacement in patients with dominant aortic stenosis are excellent, and advanced age alone should not be regarded a contraindication for aortic valve replacement in otherwise healthy patients.

1 Lombard JT, Selzer A. Valvular aortic stenosis: a clinical hemodynamic profile of patients. Ann Int Med 1987, 106:292-8.

2 Selzer A. Changing aspects of the natural history of aortic stenosis. N Engl $\Im$ Med 1987;317:91-8.

3 Roger VL, Tajik AJ, Bailey KR, Oh JK, Taylor CL Seward JB. Progression of aortic stenosis in adults: new appraisal using Doppler echocardiography. Am Heart $\mathcal{f}$ 1990;119:331-8.

4 Otto CM, Pearlman AS, Gardner CL. Hemodynamic progression of aortic stenosis in adults assessed by Dopple echocardiography. $\mathcal{F}$ Am Coll Cardiol 1989;13:545-50.

5 Wagner S, Selzer A. Patterns of progression of aortic stenosis: a longitudinal hemodynamic study. Circulation 1982,58:77-89.

6 Barnhorst DA, Guiliani ER, Pluth JR, Danielson GK, Mallace RB, McGoon DC. Open heart-surgery in
patients more than 65 years old. Ann Thorac Surg patients more

7 Hirshfeld JW, Epstein SE, Roberts AJ, Glancy DL, Morrow AG. Indices predicting long-term survival afte valve replacement in patients with aortic regurgitation and aortic stenosis. Circulation 1974;50:1190-9.

8 Pellegrini A, Marcazzan E, Peronace B, DeCasperis C, Gordini V, Mombelloni G. Ten years experience in heart valve replacement with artificial prostheses: Immediate and long-term results in 1812 cases. f Cardiovasc Surg (Torino) 1975;16:612-25

9 Schuster P, Trieb G, Sturm A. Zur Problematik von Diagnostik und Therapie erworbener Herzklappenfehler bei Patienten in höherem Lebensalter. $Z$ Gerontol 1985;18:305-12.

10 Ahmad A, Starr A. Valve replacement in geriatric patients. Br Heart f 1969;31:322-6.

11 Austin WG, Desanctis W, Buckley MJ, Mundt ED, Scannel JG. Surgical management of aortic stenosis in Scannel JG. Surgical management
the elderly. $\mathscr{F} A M A$ 1970;211:624.

12 Bowles LT, Hallman GL, Cooley DA. Open heart surgery in patients over sixty years of age. $尹 \mathrm{Am}$ Geriatr $\mathrm{Soc}$ 1969;17:817.

13 Copeland JG, Griepp RB, Stinson EB, Shumway NE. Isolated aortic valve replacement in patients older than 65 years. $¥ A M A$ 1977;237:1578.

14 Dalichau H, Hannekum A, Lie TB. Herzklappenersatzchirurgie im höheren Lebensalter. Lebensversicherungsmedizin 1982;34:9.

15 Guthrie RB, Spellenberg RD, Benedict JS. Open-heart valve surgery in patients 65 and older. Arch Sur 1972;105:42.

16 Jegaden O, Devolfe C, Coll J, Adeleine P, Beaune J, Delaye J, Mikaeloff P. Remplacement valvulaire aortique isole a un stade evolue d'insuffisance cardiaque Resultats et etude prognostiqu

17 Cabrol C, Bensaid J, Dumeix J, Blanc G, Acar J, Morin B. Risques et resultats á moyen term du remplacement B. Risques et resultats á moyen term du remplacement
valvulaire aortique pour sténose calcifiée chez 100 sujets valvulaire aortique pour sténose calcifiee chez 100

18 Glock Y, Pecoul R, Cerene A, Laguerre J, Puel P. Aortic valve replacement in elderly patients. $\mathcal{f}$ Cardiovasc Surg 1984;25:205-10.

19 Pflug $M$, et al. Aortic valve replacement in older patients. Schweiz Med Wochenschr 1982;112:634-8.
20 Carabello BA, Green LH, Grossmann W, Cohn LH, Koster JK, Collins J. Hemodynamic determinants of prognosis of aortic stenosis and advanced congestive heart failure. Circulation 1980;62:42.

21 Carabello BA, Williams H, Gash AK, Kent R, Belber D, Maurer A, et al. Hemodynamic predictors of outcome in patients undergoing valve replacement Circulation 1986;74:1309-16.

22 Vanetti A, Donzeau-Gouge GP, Peres S, Daumet P. Remplacement valvulaire aortique chez 34 operes de Remplacement valvulaire aortique chez 34 op 70 ans. Arch Mal Coeur 1980;9:1103-10.

23 Levinson JR, Akins CW, Buckley MJ, et al. Octogenarians with aortic stenosis: outcome after aortic valve replacewith aortic stenosis: outcome after aortic
ment. Circulation 1989;80(suppl I):49-56.

24 Lund $O$. Preoperative risk evaluation and stratification of long-term survival after valve replacement for aortic stenosis. Reasons for earlier operative intervention. Circulation 1990;82:124-39.

25 Lund $O$, Vaeth M. Prediction of late results following valve replacement in aortic valve stenosis. Seventeen years of follow-up examined with the Cox regression analysis. Thorac Cardiovasc Surg 1987;35:295-303.

26 Sethi GK. Should aortic valve replacement be performed in elderly patients? Ann Thorac Surg 1988;46:262-3.

$27 \mathrm{Di}$ Lello F, Flemma RJ, Anderson AJ, Mullen DC, Kleinman LH, Werner PH. Improved early results after aortic valve replacement: analysis by surgical time frame. Ann Thorac Surg 1989;47:51-6.

28 Fremes SE, Goldman BS, Ivanov J, Weisel RD, David TE, Salerno T. Valvular surgery in the elderly. Circulation 1989;80(suppl I):77-90.

29 Craver JM, Weintraub WS, Jones EL, Guyton RA, Hatcher CR Jr. Predictors of mortality, complications, and length of stay in aortic valve replacement for aortic stenosis. Circulation 1988;78(suppl I):85-90.

30 Edmunds LH Jr, Stephenson LW, Edie RN, Ratcliffe MB. Open heart surgery in octogenarians. $N$ Engl $\mathcal{F} \mathrm{Med}$ 1988;319:131-6.

31 Freeman WK, Schaff HV, O'Brien PC, Orszulak TA, Naessens JM, Tajik AJ. Cardiac surgery in the octogenarian: perioperative outcome and clinical follow-up. f Am Coll Cardiol 1991;18:29-35.

32 Culliford AT, Galloway AC, Colvin SB, Grossi EA, Baumann FG, Esposito R, et al. Aortic valve replacement for aortic stenosis in persons aged 80 years and over. Am $¥$ Cardiol 1991;67:1256-60.

33 Krayenbühl HP, Hess OM, Schneider J, Turina M. Regression der Myokardhypertrophie bei Aortenvitien Regression der Myokardhypertrophie bei Aortenvitien nach Aortenklappen

34 Krayenbüh HP, Hess OM, Monrad ES, Schneider J, Mall $G$, Turina $M$. Left ventricular myocardial structure in aortic valve disease before, intermediate, and late after aortic valve replacement. Circulation 1989;79:744-55.

35 Kuntz RE, Tosteson NA, Berman AD, Goldman L, Gordon PC, Leonard BM, et al. Predictors of event-free survival after balloon aortic valvuloplasty. $N$ Engl f Med 1991;325:17-23.

36 Sethi GK, Miller DC, Soucheck J, et al. Clinical, hemodynamic and angiographic predictors of operative mortality in patients undergoing single valve replacement. f Thorac Cardiovasc Surg 1987;93:844.

37 Hammermeister KE, Cantor AB, Burchfiel CM, Sethi GK, Hong DM. Clinical, haemodynamic and angioraphic predictors of survival in unoperated patients graphic predictors of survival in unoperated patients

38 Hoffmann A, Vogt S, Roth J, Grädel E, Althaus U, Goy JJ, et al. Der Einfluss präoperativer Befunde auf das Spätresultat. Schweiz Med Wochenschr 1992;122: 1907-10.

39 Sechtem U, Müller-Haake RC. Coronary artery disease in aortic stenosis. $Z$ Kardiol 1986;75(suppl 2):86-9.

40 Richardson JV, Kouchoukos NT, Wright JO, Karp RB. Combined aortic valve replacement and myocardial revascularisation: Results in 220 patients. Circulation 1979;59:75-81.

41 Wisoff BG, Fogle R, Weisz D, Garvey J, Hamby $R$. Combined valve and coronary artery surgery. $A n n$ Thorac Surg 1980;29:440-6.

42 Cormier $B$, Luxereau $P$, Bloch $C$, Ducimetiere $P$, Boustani F, Badaoui G, et al. Prognosis and long-term results of surgically treated aortic stenosis. Eur Heart $f$ 1988;9(suppl E):113-20.

43 Bessone LN, Pupello DF, Hiro SP, Lopez-Cuenca E, Glatterer MS, Ebra G. Surgical management of aortic valve disease in the elderly: a longitudinal analysis. Ann Thorac Surg 1988;46:264-9.

44 Cohn LH. The long-term results of aortic valve replacement. Chest 1984;85:387-96.

45 Lytle BW. Combined surgery for valve and coronary artery disease. Cleve Clin $\mathcal{Y}$ Med 1988;55:79.

46 Hancock EW. Timing of valve replacement for aortic stenosis. Circulation 1990;82:310-2. 